\title{
ANÁLISE DA RELAÇÃO DA DINÂMICA DA PAISAGEM COM A CRISE HÍDRICA EM IRAÍ DE MINAS/MG
}

Aracy Alves de Araújo ${ }^{1}$ Janderson Cristian Ferreira ${ }^{2}$ Claudionor Ribeiro da Silva ${ }^{3}$

Resumo: $O$ município de Iraí de Minas/MG passou por um intenso processo de expansão agropecuária e por uma crise hídrica no abastecimento urbano. O objetivo desse estudo foi analisar a dinâmica da paisagem e seus efeitos nos recursos hídricos, no período de 1984 a 2015. Para tanto, foi aplicada a aritmética de bandas espectrais: o NDVI (índice de vegetação da diferença normalizada) e a subtração de imagens nas cenas Landsat5/TM-1984 e Landsat8/OLI-2015. Os resultados comprovam uma forte alteração da paisagem, especialmente com a implantação da pecuária e agricultura mecanizada (passando de $14.01 \%$ para $70.78 \%$ da área total do município), fatores que acarretam o uso intenso da água e, consequentemente, na redução do nível d’água de um rio.

Palavras-Chave: Dinâmica da Paisagem. Iraí de Minas. NDVI. Agropecuária. Imagem digital.

\section{TEMPORAL ANALYSIS OF THE LANDSCAPE DYNAMICS AND HYDRICAL CRISIS IN IRAÍ DE MINAS/MG}

Abstract: The municipality of Iraí de Minas (Minas Gerais, Brazil) has undergone an intense process of agricultural expansion and a water crisis in the urban supply. The objective of this study was to analyze the dynamics of the landscape and its effects on water resources, from 1984 to 2015. To do so, the arithmetic of spectral bands was applied: NDVI (normalized difference vegetation index) and image subtraction in the scenes Landsat5/TM-1984 and Landsat8/OLI-2015. The results show a strong alteration of the landscape, especially with the implantation of livestock and mechanized agriculture (from $14.01 \%$ to $70.78 \%$ of the total area of the municipality), factors that cause the intense use of water and, consequently, in the reduction of the water level of a river.

Keywords: Landscape dynamics. Iraí de Minas. NDVI. Farming. Digital image.

\section{ANÁLISIS DE LA RELACIÓN DE LA DINÁMICA DEL PAISAJE CON LA CRISIS HÍDRICA EN IRAÍ DE MINAS/MG}

Resumen: El municipio de Iraí de Minas, Minas Gerais, Brasil, pasó por un intenso proceso de expansión agropecuaria y por una crisis de recursos hídricos para el abastecimiento urbano. El objetivo de ese estudio fue el análisis de la dinámica del paisaje y sus efectos en los recursos hídricos durante el periodo comprendido entre 1984 y 2015. Para esto, se aplicó la aritmética de las bandas espectrales: el NDVI (Índice de vegetación de diferencia normalizada) y la substracción de imágenes de las escenas Landsat5/TM-1984 y Landsat8/OLI-2015. Los resultados demostraron

\footnotetext{
${ }^{1}$ Universidade Federal de Uberlândia, Faculdade de Gestão e Negócios, Uberlândia, Brasil, aracy@ufu.br, https://orcid.org/0000-0002-5497-5159

2 Universidade Federal de Uberlândia, Programa de Pós-Graduação em Qualidade Ambiental ICIAG, Uberlândia, Brasil, janderson@ufu.br, https://orcid.org/0000-0002-6356-014X

${ }^{3}$ Universidade Federal de Uberlândia, Instituto de Geografia, Uberlândia, Brasil, crs@ufu.br, https://orcid.org/0000-0003-4542-0933
} 
que existe una fuerte alteración del paisaje, especialmente debido a la implementación de la ganadería y la agricultura mecanizadas (pasando del $14.01 \%$ al $70.78 \%$ del área total del municipio), factores que llevan al uso intensivo del agua y, en consecuencia, a la reducción del nivel de agua de un río.

Palabras Clave: Dinámica del paisaje. Iraí de Minas. NDVI. Agricultura. Imagen digital.

\section{Introdução}

O Cerrado ocupa $21 \%$ do território nacional e representa o segundo maior bioma brasileiro, superado apenas pela Amazônia. É considerado a última fronteira agrícola do planeta (BORLAUG, 2002). Esse bioma vem sendo explorado pelo homem, de forma insustentável, para práticas de agricultura e pecuária intensivas. Estudos apontam o Cerrado como um dos hotspots mundiais de biodiversidade, isto é, apesar de ser um dos biomas mais ricos do planeta, também é um dos mais ameaçados (MYERS et al., 2000; SILVA e BATES, 2002).

Mais da metade do Cerrado foi transformado em pastagens plantadas e/ou utilizado para outros tipos de ocupação do solo. Estudos realizados no ano de 2002 já mostravam que $54.9 \%$ da área do Cerrado haviam sido desmatados ou transformados pela ação antrópica. Atualmente, as taxas anuais de desmatamento variam entre 22.000 e $30.000 \mathrm{~km}^{2}$ (MACHADO et al., 2004). Segundo Klink e Machado (2005) pouco mais de $11 \%$ do bioma é utilizado para práticas agrícolas, enquanto cerca de $41.56 \%$ é constituído de áreas de pastagens. Eles demonstraram ainda que, as transformações ocorridas no Cerrado provocam grandes danos ambientais, como alterações climáticas de âmbitos regionais provocadas pelo desequilíbrio dos ciclos biogeoquímicos, além de fragmentar os habitats dos animais, extinguir a biodiversidade, permitir que espécies exóticas substituam as nativas, acelerar a erosão do solo, ainda pode ocasionar a poluição de aquíferos.

A antropização, ou uso da Terra, é entendida como a forma de ocupação do espaço pelo homem e cuja importância se dá na medida em que os efeitos do uso desordenado causam deterioração no ambiente. Nesse contexto, Krug (1999) destaca a importância das geotecnologias para a exploração de informações de diferentes áreas de estudo e cujas análises das imagens digitais constituem-se de importantes fontes de informação necessárias ao manejo, gerenciamento e gestão dos recursos naturais, como água, solo e vegetação. Destaca ainda que para países com dimensões continentais, como o Brasil, o uso dessa tecnologia espacial é imprescindível. 
O sensoriamento remoto e as técnicas de processamento digital de imagens são parte das geotecnologias que podem ser usadas para mensurar alterações ambientais em nível local, regional ou global. Segundo Novo (1989) e Richards (1986) o sensoriamento remoto pode ser definido como sendo a utilização conjunta de sensores e equipamentos para processamento e transmissão de dados objetivando o estudo do ambiente terrestre por meio da análise interativa entre a radiação eletromagnética e as substâncias componentes da superfície. Graças a essas interações, é possível distinguir os objetos presentes na superfície terrestre por meio das imagens de sensores remotos (FLORENZANO, 2011).

A série Landsat, atualmente com 8 satélites, é gerenciada pela agência espacial americana (NASA), e disponibiliza, gratuitamente, séries históricas de imagens digitais que possibilitam estudos ambientais detalhados. O sensor TM (thematic mapper), acoplado no Landsat 5, gerou imagens com seis bandas espectrais, com resolução espacial de 30 metros e radiométrica de 8 bits, e o sensor OLI (Operational Land Imager), acoplado no Landsat 8, gera oito imagens com mesma resolução espacial (30 metros), mas com resolução radiométrica de 16 bits. São imagens capazes de mostrarem detalhes na superfície terrestre (INPE, 2016).

As técnicas de processamento de imagens digitais atuam no sentido de melhorar a percepção/contraste dos detalhes dos objetos presentes nas cenas. A aritmética de bandas (subtração, soma, divisão e multiplicação) é uma dessas técnicas e que tem ganhado destaque especialmente com o surgimento dos índices espectrais, como o de vegetação NDVI (Normalize Difference Vegetation Index), proposto por Rouse et al. (1974). Meneses e Almeida (2012) afirmam que a subtração de bandas permite detectar mudanças (change detection) temporais de alvos/fenômenos, como a detecção de impactos ambientais, desmatamentos e queimadas florestais. É recomendado aplicar essa técnica em imagens de datas diferentes, mas preferencialmente de sensor com características similares, para evitar detecção de mudanças irreais. Por outro lado, o uso do índice NDVI, que normaliza a radiância no intervalo [-1 1], minimiza esse erro além de reduzir efeitos da interferência atmosférica. Os valores de NDVI próximos ou iguais a 1 (um) estão relacionados com a vegetação fotossinteticamente ativa; os valores NDVI próximo de zero referem-se a área com solos; e os valores de NDVI negativos, próximos a 1, indicam a presença de corpos d'água (PONZONI e SHIMABUKURO, 2010). 
O município de Iraí de Minas/MG, que se encontra inserido no bioma Cerrado, corresponde à área de estudo dessa pesquisa. Nas últimas décadas a área desse município passou por alterações de uso e ocupação do solo, decorrentes especialmente das atividades agropecuárias. Muito em razão dessa alteração da paisagem, a zona urbana passou por uma grave crise hídrica, fato ocorrido devido à redução do nível d’água do rio Bagagem, responsável pelo abastecimento da cidade. Nesse contexto, o objetivo deste estudo foi analisar as mudanças de paisagens ocorridas e seus efeitos em um determinado lapso temporal, no município de Iraí de Minas/MG, com uso de imagens orbitais. Essa análise foi realizada em produtos gerados a partir da subtração de bandas e uso dos índices NDVI calculados em datas distintas, nos anos de 1984 e 2015.

\section{Metodologia \\ Área de estudo}

A área de estudo compreende o município de Iraí de Minas (Figura 01). De acordo com IBGE (2016), o município de Iraí de Minas/MG, localizado na região do Triângulo Mineiro, a sudoeste do Estado de Minas Gerais, possui uma população estimada para 2016 de 6929 habitantes, sendo aproximadamente $80 \%$ de residentes na área urbana. Fundado em 1962, o município encontra-se completamente no Bioma Cerrado, ocupando uma área territorial de $356.264 \mathrm{Km}^{2}$. O município limita-se a leste com Romaria e Nova Ponte, a oeste com Patrocínio e Perdizes, ao norte com Monte Carmelo e ao sul com o município de Pedrinópolis (GENARO, 2016).

Historicamente, Iraí de Minas tem forte ligação com o rio Bagagem, que constitui o principal recurso hídrico da região. Devido à exploração de jazidas minerais e da descoberta do diamante estrela do sul em 1852, uma grande quantidade de garimpeiros aglomeraram-se em torno do rio e ali deixavam suas bagagens, o que levou à denominação de rio Bagagem. No ano de 1943, o pequeno povoado também recebeu o nome de Distrito de Bagagem e somente em 1953 definiu-se o nome atual, cujo significado, na linguística tupi-guarani, é Rio de Mel. Em 1962, pela Lei no 2764 de 30/12/1962 Iraí de Minas foi desmembrado de Monte Carmelo e reconhecido como município. Conforme dados disponíveis em IBGE (2016), a economia do município baseia-se em atividades agropecuárias, como a produção de leite, gado de corte, plantação de milho, soja, trigo, feijão, batata, cebola e outras plantações de entressafra menos importantes, além de algumas áreas com atividades de agricultura familiar, voltada para a subsistência. 


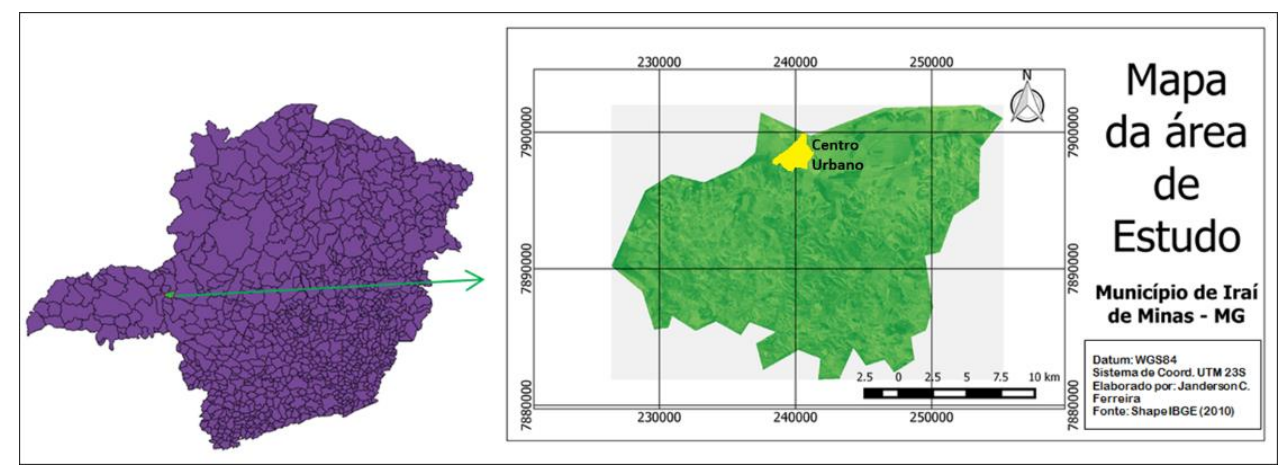

Figura 01. Mapa de localização da área de estudo.

Fonte: Os autores, 2016.

\section{Material}

Para analisar a dinâmica da paisagem que ocorreu na região nas últimas três décadas foram utilizadas duas cenas, sendo uma do satélite Landsat 5/TM, do ano de 1984, e outra cena do Landsat 8/OLI, do ano de 2015. As imagens foram baixadas através do catálogo de imagens do Instituto Nacional de Pesquisas Espaciais (INPE, 2016). Ambas as imagens estavam em projeção UTM, Fuso 23S, resolução espacial de 30 metros, Sistema de referência WGS84. As características das imagens obtidas são descritas na Tabela 01.

Tabela 01. Descrição das imagens obtidas dos satélites Landsat 5 e 8.

\begin{tabular}{lcc}
\multicolumn{1}{c|}{ Satélite } & Landsat 5 (8 bits) & Landsat 8 (16 bits) \\
\hline Data Aquisição & $07 / 08 / 1984$ & $10 / 06 / 2015$ \\
Ponto/Órbita & $220 / 073$ & $220 / 073$ \\
Intervalo espectral (Bandas 01 a 07) & $0.45-2.35 \mu \mathrm{m}$ & $0.43-2.29 \mu \mathrm{m}$
\end{tabular}

Fonte: Instituto Nacional de Pesquisas Espaciais (INPE, 2016).

O shape de limite dos municípios foi obtido gratuitamente no site do IBGE (Instituto Brasileiro de Geografia e Estatística). O processamento das imagens foi realizado com o software Envi 4.8 §, disponível no Laboratório de Sensoriamento Remoto e Fotogrametria da Universidade Federal de Uberlândia. 


\section{Método}

O método proposto foi dividido em três fases: pré-processamento, subtração de bandas espectrais e cálculo do índice NDVI. Para melhor entendimento da metodologia proposta, é apresentado um fluxograma na Figura 02.

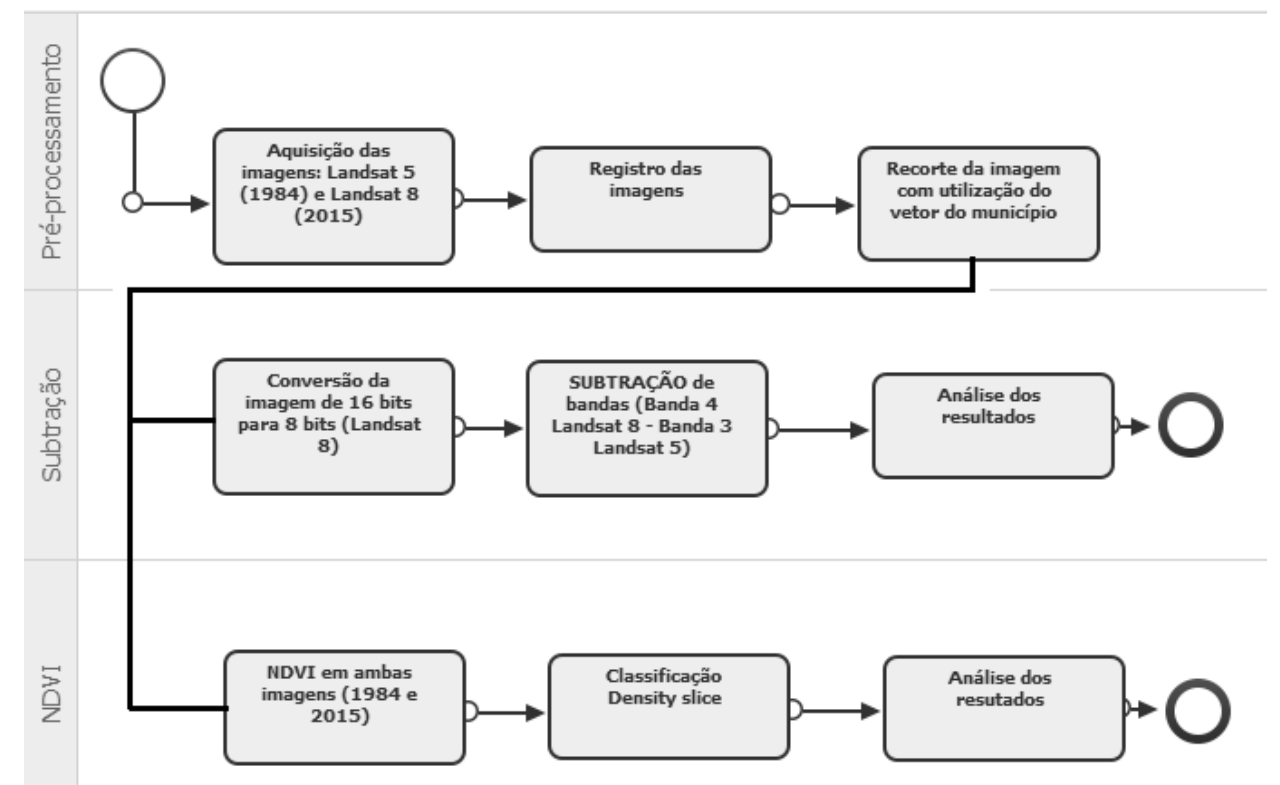

Figura 02. Fluxograma da metodologia.

Fonte: Os autores, 2016.

Iniciando a primeira etapa da metodologia, foi recortada a imagem de forma que o recorte contivesse a área de estudo. Em seguida, para realizar o registro das duas imagens (Landsat 5 e 8) foram criadas duas composições coloridas: 3R4G2B (Landsat 5) e 4R5G3B (Landsat 8), usando a imagem do Landsat 8 como base. $O$ registro foi realizado com um total de 30 pontos de controle, coletados com distribuição adequada dentro da área de estudo, com erro médio quadrático (RMS) menor que um pixel. Ambas as imagens foram recortadas usando 0 arquivo vetorial (shape) obtido junto ao IBGE, que delimita o município (Figura 01). Ainda nessa fase, a imagem do Landsat $8 / \mathrm{OLI}$ foi convertida de 16 para 8 bits, para ficar compatível com a imagem do Landsat 5/TM.

$\mathrm{Na}$ segunda etapa da metodologia foi realizada a aritmética de bandas, operação de subtração, com intuito de quantificar as mudanças mais expressivas ocorridas na paisagem. Segundo Meneses e Almeida (2012) essa técnica necessita de duas imagens de datas diferentes ( $g 1$ e $g 2$ ), mas referentes ao mesmo comprimento de onda da radiação eletromagnética. A imagem gerada da subtração 
resulta em uma diferença mínima negativa de -255 e máxima positiva de +255. Uma vez que não existe radiância de energia negativa, o algoritmo adiciona 255 e o intervalo digital passa a ter uma amplitude que varia entre 0 a 511. Esses valores são divididos por 2 e assim resulta em uma imagem reescalonada entre 0 e 255, conforme Equação 1. Os valores intermediários, próximos a 128, indicam a ausência de mudança, já os valores próximos de zero ou de 255 indicam mudanças ao longo do período analisado.

$$
g_{d i f}=\frac{(g 1-g 2)+255}{2}
$$

Como elemento $g 1$, do processo de subtração, foi utilizada a imagem da banda 4 (banda vermelha "red", intervalo espectral de 0.64 a $0.67 \mu \mathrm{m}$ ), do Satélite Landsat 8/OLI, referente ao ano de 2015 , e, como $g 2$, foi utilizada a imagem gerada na banda 3 (banda vermelha "red", intervalo espectral de 0.63 a $0.69 \mu \mathrm{m}$ ) do Satélite Landsat 5/TM, referente ao ano de 1984. Estas duas bandas foram utilizadas porque, segundo INPE (2016), a banda do vermelho apresenta características importantes para este tipo de estudo, como o bom contraste entre as áreas verdes ocupadas com vegetação e com os diferentes tipos de cobertura vegetal (ex: campo, cerrado, floresta), além de permitir com facilidade a visualização dos entalhes de cursos dos rios, de áreas agrícolas e é bastante utilizada para delimitar a mancha urbana. $O$ resultado da subtração é uma imagem onde são destacados os principais locais com diferenças significativas na paisagem.

Em seguida, por meio da imagem "subtraída", foram identificadas as áreas de irrigação (pivô central) que fazem captação de água diretamente dos afluentes do rio Bagagem. Essas áreas de irrigação foram extraídas da imagem "subtração", utilizando a ferramenta de medição de figuras do software Envi $4.8 \AA$, e a área total foi calculada multiplicando a quantidade de pixel pela resolução da imagem $\left(900 \mathrm{~m}^{2}\right)$. Para o cálculo da demanda total de água de uma safra anual foi utilizado o modelo (Equação 2) proposto por Sano et al. (2007). Nesse modelo, a demanda hídrica total (Dt) em $\mathrm{m}^{3}$ é obtida através do produto da área irrigada total $(\propto)$ por uma constante de demanda hídrica média anual por safra, igual a 0.6.

$$
D t=\Sigma(\propto * 0.6)
$$


Por fim, na terceira etapa foi calculado o NDVI, utilizando as bandas 3 (vermelho - R) e 4 (Infravermelho próximo - NIR) da imagem de 1984 e bandas 4 (vermelho - R) e banda 5 (Infravermelho próximo - NIR) da imagem de 2015. Meneses e Almeida (2012) afirmam que o NDVI é mais apropriado para analisar mudanças ocorridas ao longo do tempo, já que sofre menos interferência das condições atmosféricas. De acordo com Rouse et al. (1974), o NDVI é calculado pela Equação 3.

$$
N D V I=\frac{(N I R-R)}{(N I R+R)}
$$

Posteriormente, essa imagem foi classificada através do método Densidade de Corte (Density slice), em cinco classes de uso, conforme a Tabela 02. Segundo ESRI (2015), a classificação de imagens pelo método "Densidade de Corte" (Density slice), aplicada a uma imagem monocromática (banda única), serve para destacar as áreas que parecem ser uniforme no tom, mas não são. Nesse método, os valores são convertidos numa série de intervalos (ou fatias) e cores diferentes são atribuídas a cada fatia.

Tabela 02. Classes de uso do solo e intervalos de NDVI de 1984 e 2015.

\begin{tabular}{l|c|c}
\hline \multicolumn{1}{c|}{ Classe de uso do solo } & $\begin{array}{c}\text { Intervalo espectral } \\
\text { do NDVI (1984) }\end{array}$ & $\begin{array}{c}\text { Intervalo espectral } \\
\text { do NDVI (2015) }\end{array}$ \\
\hline Água & -0.550 a -0.122 & -0.173 a -0.025 \\
Solo exposto e áreas urbanas & -0.122 a 0.163 & -0.025 a 0.224 \\
Vegetação rasteira (gramíneas) & 0.163 a 0.306 & 0.224 a 0.272 \\
Vegetação primária (pouco densa) & 0.306 a 0.448 & 0.272 a 0.390 \\
Vegetação secundária (densa) & 0.448 a 0.589 & 0.390 a 0.569 \\
\hline
\end{tabular}

Fonte: Os autores, 2016.

Por meio da ferramenta estatística (Generate Random Sample - Using Ground Truth Classification Image), implementada no Envi 4.8 ®, foi possível comparar, em termos percentuais, quanto houve de mudança em cada classe de uso no período analisado. Esse procedimento permitiu comparar a dinâmica de mudanças ocorridas na paisagem em estudo. 


\section{Resultados e discussões}

Através do processo de subtração de bandas foi possível verificar as diferenças espectrais ocorridas nas imagens dos anos de 1984 e 2015. Tais diferenças podem ser observadas na Figura 03, as quais, segundo Meneses e Almeida (2012) demonstram que os tons de cinza mais escuros e mais claros correspondem às áreas que sofreram maior mudança.

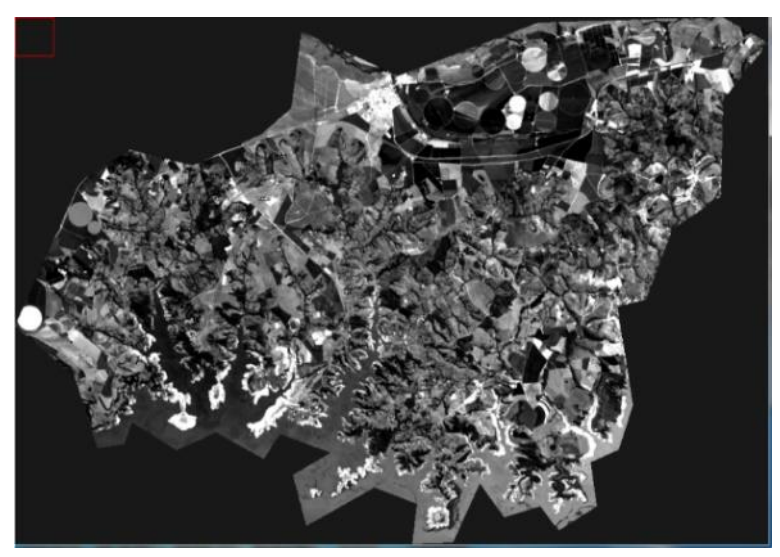

Figura 03. Imagem subtraída (banda 4 Landsat 8 - banda 3 Landsat 5).

Fonte: Os autores, 2016.

As áreas mais escuras (Figura 03) concentram-se principalmente nas regiões norte e nordeste do município, mais à montante do rio Bagagem. Estas áreas representam, in loco, a região com maior quantidade de práticas agrícolas intensivas dentro do município. No ano de 1984 essas áreas haviam passado por desmatamento, por isso apareciam com solo descoberto. Ao contrário, no ano de 2015 essas áreas eram cultivadas durante o ano inteiro, graças à prática de irrigação, que se dá especialmente por uso de pivô central, e outras áreas de café que utilizam práticas de gotejamento. Algumas áreas escuras em regiões mais centralizadas no município demonstram que houve desmatamento no período em estudo, ocorrendo a substituição da floresta primária (cerrado sensu lato, sensu strictu e cerradão) por culturas exóticas, como café, eucalipto ou culturas forrageiras para criação de gado bovino, utilizando-se principalmente a Brachiaria spp (braquiária). Esse fato foi validado in loco.

A imagem subtraída permite também observar áreas esbranquiçadas, localizadas mais ao norte da imagem, representando a mancha urbana e retratando que houve um aumento do tamanho da cidade, provocado pelo êxodo rural das últimas décadas, como mostrado em Genaro (2016). Outros pontos brancos 
retratam ausência de vegetação, seja por gradeamento para novos cultivares ou áreas próximas à lagoa hidrelétrica de Nova Ponte, cujo nível da água baixou, deixando o solo descoberto (região mais ao sul).

A evolução agrícola no município é evidente nesse estudo, pois, enquanto no ano de 1984 inexistiam culturas irrigadas, no ano de 2015 foram extraídas 25 parcelas agrícolas referentes a somente a prática de irrigação por pivô central, sendo que 22 dessas parcelas (88 \%) localizam-se à montante do rio Bagagem, mostrando que atualmente a atividade agrícola no município é altamente dependente deste recurso hídrico. Essas áreas irrigadas que captavam água diretamente do rio Bagagem, ou de seus afluentes, somaram uma área total de aproximadamente $1009.00 \mathrm{ha}$, conforme a Tabela 03.

Tabela 03. Áreas irrigadas extraídas à montante do rio Bagagem

\begin{tabular}{cc|c|c}
\hline Área extraída & Área medida (ha) & Área extraída & Área medida (ha) \\
\hline 1 & 28.2600 & 12 & 40.6944 \\
2 & 28.2600 & 13 & 40.6944 \\
3 & 113.0400 & 14 & 113.0400 \\
4 & 78.5000 & 15 & 12.5600 \\
5 & 78.5000 & 16 & 28.2600 \\
6 & 40.6944 & 17 & 50.2400 \\
7 & 33.1663 & 18 & 45.3416 \\
8 & 33.1663 & 19 & 70.8463 \\
9 & 15.8963 & 20 & 63.5850 \\
10 & 15.8963 & 21 & 23.7463 \\
11 & 15.8963 & 22 & 39.2500 \\
\hline
\end{tabular}

Fonte: Os autores, 2016.

A maioria dos cultivares agrícolas dessas áreas, em específico, é constituída de plantações de trigo e outros grãos, como feijão, milho e soja. Segundo Sano et al (2007), esses tipos de culturas demandam cerca de $500 \mathrm{~mm}$ de água em períodos secos e $100 \mathrm{~mm}$ de água em períodos de veranico, totalizando uma demanda de água para irrigação de $600 \mathrm{~mm}$ por safra. Assim, considerando a área irrigada a montante do rio Bagagem, no ano de 2015, e fazendo as devidas conversões de unidades, o consumo de água desses equipamentos foi estimado em 6.06 milhões de metros cúbicos por ano. 
Segundo o Relatório 6 da Superintendência Regional da Companhia de Pesquisa de Recursos Minerais de Belo Horizonte (CPRM, 2014), a vazão mínima medida no rio Bagagem, em Iraí de Minas, até o ano de 2013, foi de 0.25 $\mathrm{m} 3 /$ segundo ou de 7.88 milhões de $\mathrm{m} 3$ anuais. Considerando esses valores, observa-se que praticamente $77 \%$ da vazão do rio foi utilizada na irrigação das áreas analisadas. Ressalta-se ainda que, em casos de estiagem prolongada, como a ocorrida no ano de 2014, período em que muitos rios da região sudeste tiveram seus níveis e vazões mínimas muito abaixo da série histórica, o rio Bagagem chegou a níveis de vazão próximos a zero, provocando a crise hídrica supracitada, pois faltou água para o abastecimento da população urbana. Segundo o mesmo relatório, a situação é ainda mais crítica para o ano de 2014, onde a vazão mínima registrada no rio Bagagem foi de $0.15 \mathrm{~m} 3 / \mathrm{segundo}$, valor este insuficiente para manter 0 abastecimento urbano e a irrigação das lavouras da região. Esse fato evidencia a causa da crise hídrica instalada no centro urbano do município.

Em suma, a utilização da subtração de bandas espectrais (bandas 3 e 4) mostrou-se eficiente no aumento do contraste de alvos que passaram por alterações ao longo do tempo. Com a imagem mais contrastada foi possível realizar uma análise visual do desenvolvimento da mancha urbana (destacada em branco) bem como do alagamento de áreas rurais nas proximidades da Represa da Hidrelétrica de Nova Ponte (RHNP). Além disso, a subtração de imagens permitiu uma análise quantitativa das áreas irrigadas, aproximadamente $3 \%$ da área do município, que nos últimos anos receberam práticas de culturas irrigadas cada vez mais intensas e mecanizadas. Esse percentual desconsidera as áreas de cultivos não irrigados.

O processamento das imagens pelo método de NDVI possibilitou a observação da variação da cobertura vegetal ocorrida entre os anos de 1984 e 2015 (Figura 04).

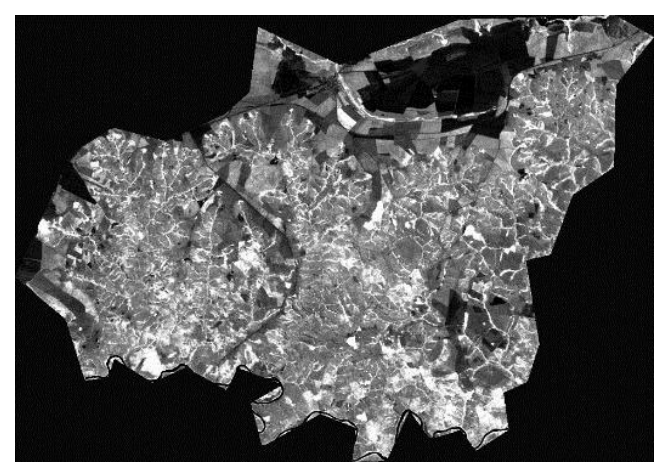

( a )

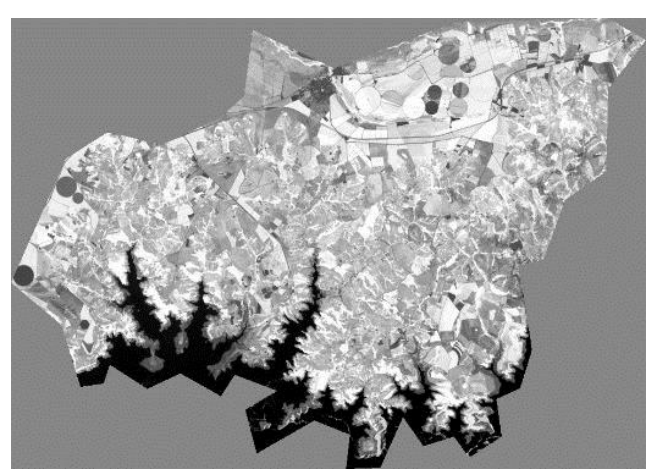

(b) 
Figura 04. Imagens de NDVI referentes aos anos de 1984 ( a ) e 2016 ( b )

Fonte: Os autores, 2016.

Observa-se grande diferença nos tons de cinza, que segundo preconizado por Rosendo (2005), tons mais claros indicam uma vegetação mais densa e tons mais escuros indicam superfícies com presença de solos e corpos d'agua. A Figura 04a apresenta tons de cinza mais escuros e algumas áreas com tons muito próximos de 0 (zero). Essa ocorrência é explicada pelo fato de que naquela época existiam poucas práticas agrícolas na região. A maioria da vegetação era composta por pastagens naturais, gramíneas e vegetação nativa do Cerrado. Já no período contemporâneo (Figura 04b) observa-se tons de cinza mais claros, indicando a grande expansão agrícola e a substituição das áreas de pastagens nativas por pastagens cultivadas. Essas modificações nas estruturas morfofisiológicas e no vigor de clorofila das plantas refletem em maior biomassa foliar, o que é perfeitamente captado nas imagens digitais, mostrando maiores valores de NDVI.

Embora as imagens de NDVI já expressam visualmente diferenças espectrais de alvos, a classificação dessas imagens torna possível rotular as classes de uso do solo e realizar análises quantitativas de cada classe (Figura 05a e 05b).

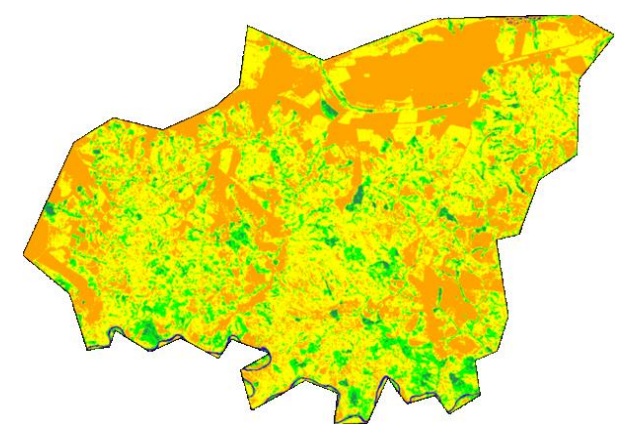

(a)

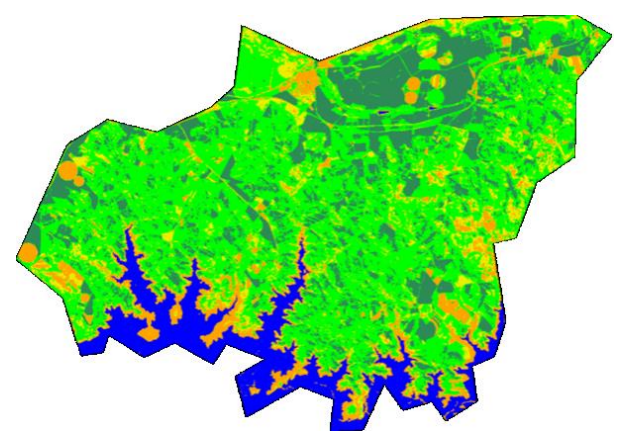

(b)

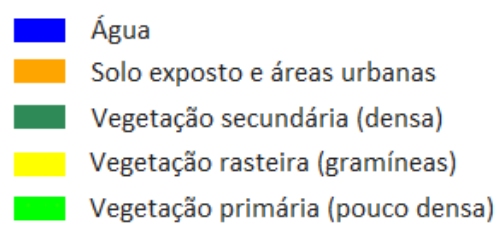

Figura 05. Imagens de NDVI classificadas referentes aos anos 1984 (a) e 2015 (b). Fonte: Os autores, 2016.

As cinco classes definidas nesse estudo representam as feições: "água", constituída pelos corpos d'água; solos expostos presentes na área de estudo; áreas 
de vegetação rasteira e de pequena área foliar (ex: campo cerrado); vegetação cujas áreas foliares podem ser consideradas intermediárias; e vegetação com grande densidade e ampla área foliar. Com base no Gráfico 01 é possível verificar a mudança de uso do solo no período estudado, isto é, nos anos de 1984 e 2015.

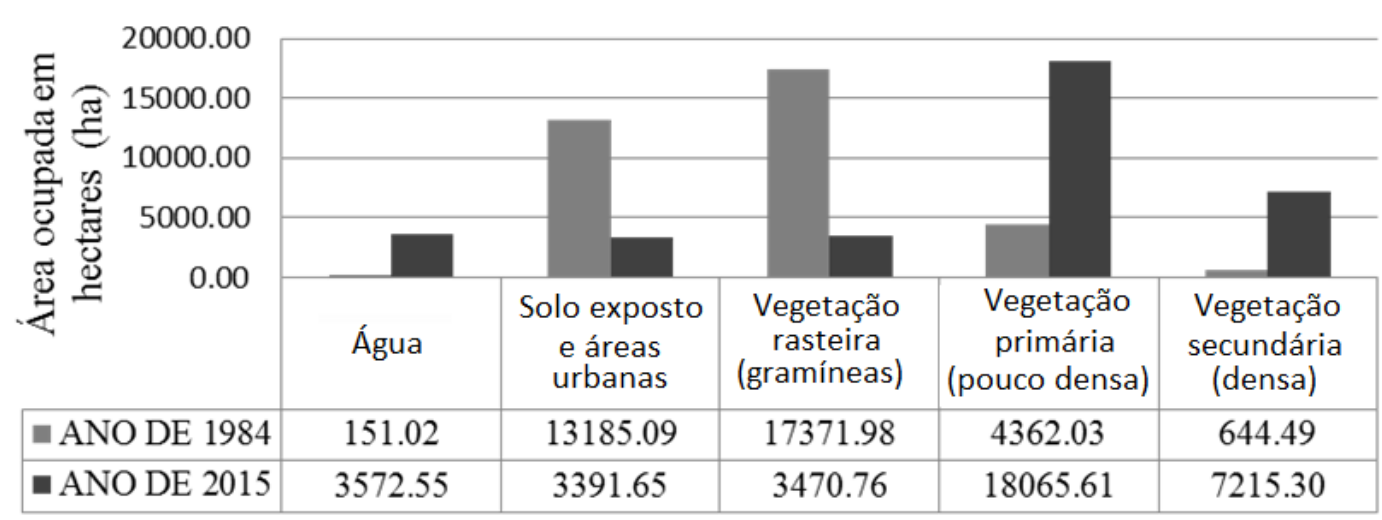

Gráfico 01. Áreas das classes de uso do solo nos anos de 1984 e 2015.

Fonte: Os autores, 2016.

O Gráfico 01 indica as mudanças ocorridas em todas as classes de uso do solo analisadas. A água, antes presente apenas nos rios e córregos, que ocupava menos de $0.5 \%$ (151.02 ha) da área total do município, passou a ocupar cerca de 10\% (3572.55 ha) devido a ação antrópica que realizou o represamento de água na RHNP. Uma simples análise sobre esse atributo pode apresentar uma falsa impressão de que existe água em abundância nessa região, no entanto, ao Norte do município, onde se localiza a área urbana, com densidade populacional de aproximadamente $80 \%$ da população (IBGE, 2016), tem ocorrido uma crise hídrica, uma vez que o rio Bagagem é a única fonte hídrica para o consumo humano, para as necessidades de saneamento básico, bem como para atender a grande demanda da agricultura irrigada do município, mas não tem fornecido vazão suficiente para toda essa demanda, como mostrado em parágrafos anteriores. Percebe-se, então, um desequilíbrio espacial na distribuição da água dentro do município, com grande abundância ao Sul e escassez ao Norte.

Quanto ao tipo de uso do solo, percebe-se na classificação do NDVI que o solo exposto (mais área urbana) somado às vegetações rasteira, características do campo cerrado (campo limpo), ocupavam mais de 85\% (30557.07 ha) da área total do município em 1984. Contudo, diminuiu para aproximadamente $19 \%$ (6862.41 ha) no ano de 2015. A substituição dessa fisionomia original se deu, em sua maior parte, 
pela plantação de pastagens que possuem maior densidade de área foliar. Esse fato foi observado in loco.

As áreas classificadas como vegetação primária, na Figura 5a, representam, de forma modesta, a vegetação de campo sujo com a presença de árvores e arbustos. Em 2015 (Figura 5b) essa classe representa a maior proporção do município $(>70 \%)$, contudo, conforme verificação in loco, foi severamente substituída, principalmente por pastagens plantadas, como as do gênero Brachiaria spp (braquiária). De forma similar, percebe-se um aumento da vegetação secundária no ano de 2015 (Figura 5b), mas o que era vegetação densa (em 1984), como o cerradão (características do cerrado Stricto Sensu), foi parcialmente substituído por plantações agrícolas, como o café, que é altamente fotossintetizante, retornando resposta espectral similar à vegetação nativa densa. Embora em menor quantidade, nessa mesma classe estão inclusas as áreas de preservação permanente (APP) e de reserva legal da região. Ressalta-se que o produto gerado nesse estudo, imagens NDVI e subtração a partir de imagens Landsat, não possibilita a separação dessa classe em mata nativa e cultivo.

Os resultados corroboram com as informações apresentadas por EMBRAPA (2014), que afirma nos seus estudos feitos desde o Censo Agropecuário de 1970 que as áreas de pastagens naturais no Brasil têm sido substituídas tanto por pastagens plantadas (capins exóticos mais produtivos - maior biomassa) quanto por lavouras e outras atividades agrícolas. Vale ressaltar que uma grande área classificada como vegetação densa em 1984, correspondente a área de APP e matas ciliares, foram suprimidas pela RHNP, alterando significativamente o cenário da região.

\section{Considerações finais}

Esse trabalho mostrou que técnicas relativamente simples de processamento digital de imagens podem ser extremamente eficientes em estudos de análise temporal, especialmente na verificação de ocorrências de alterações de feições presentes na superfície terrestre, como áreas vegetadas, agrícolas e corpos hídricos.

Através das técnicas empregadas concluiu-se que mais de $10 \%$ da área territorial do município de Iraí de Minas foi inundada pela RHNP e que ocorreram alterações significativas no uso do solo nos últimos anos, especialmente com a expansão agrícola mecanizada, fato que ocorreu em todo o Brasil no período 
analisado. Essas alterações suprimiram a vegetação natural existente na década de 1980, dando lugar às pastagens com maior biomassa foliar e às práticas agrícolas intensas. De acordo com o observado nesse estudo, a implantação da agricultura intensa nas proximidades do rio Bagagem, principal rio que abastece o centro urbano, gerou um déficit de vazão e uma consequente crise hídrica no abastecimento da população urbana e dos serviços de saneamento básico.

Estudos como esse são imprescindíveis para um monitoramento ambiental eficiente, e são capazes de fornecer subsídios reais para uma educação ambiental, focada em mostrar resultados concretos em nível local ou regional. A clareza disso está no fato ocorrido com a crise hídrica que não teria ocorrido se os gestores tivessem apoiado em dados quantitativos (como vazão do rio e demanda para irrigação) como esses apresentados nesse estudo. É fato que a agricultura intensa acarreta em crescimento econômico para uma região, mas é preciso uma gestão eficiente dos recursos hídricos, proporcionando um desenvolvimento sustentável para não gerar problemas futuros mais sérios, às vezes irreversíveis. Assim, é necessário que o poder público invista em tecnologias, em fiscalização, em conscientização ambiental e que os agricultores utilizem práticas adequadas de manejo visando otimizar o sistema de irrigação e minimizar os problemas causados pela crescente demanda hídrica. Obviamente que para isso novas pesquisas devem ser desenvolvidas a fim de oferecer subsídios técnicos em cada caso analisado.

\section{REFERÊNCIAS}

BORLAUG, N. E. Feeding a world of 10 billion people: the miracle ahead. Vitro Cellular \& Developmental Biology-Plant, v. 38, n. 2, p. 221-228, 2002.

CPRM. Companhia de Pesquisa de Recursos Minerais. Acompanhamento da estiagem na região sudeste do Brasil. Relatório 6. Belo Horizonte: Serviço Geológico do Brasil, 2014. Disponível em: http://www.cbhdoce.org.br/wp-content/uploads/2015/01/6\%C2\%BARelat\%C3\%B3rio-de-Acompanhamento-da-Estiagem-na-Regi\%C3\%A3o-Sudeste-do-Brasil2014-CPRM.pdf. Acesso em 12 dez. 2015.

SILVA, J. M. C; BATES, J. M. Biogeographic Patterns and Conservation in the South American Cerrado: A Tropical Savanna Hotspot The Cerrado, which includes both forest and savanna habitats, is the second largest South American biome, and among the most threatened on the continent. BioScience, [s.i.], v. 52, n. 3, p.225-234, 2002.

EMBRAPA. Empresa Brasileira de Pesquisa Agropecuária. Diagnóstico das pastagens no Brasil 2014. Documentos. Disponível em: http://www.infoteca.cnptia.embrapa.br/infoteca /bitstream/doc/986147/1/DOC402.pdf_Acesso em 04 dez. 2015.

ESRI. Densite slicing. 2015. Disponível em: http://support.esri.com/other-resources/gisdictionary/term/density\%20slicing. Acesso em 04 dez. 2015. 
FLORENZANO, Teresa G. Iniciação em sensoriamento remoto. 3 ed. São Paulo: Oficina de Textos, 2011.

GENARO, Felipe. A campesinidade em Iraí de Minas - MG: estratégias de reprodução social no Cerrado mineiro. 2016. 136f. Dissertação (mestrado em geografia) - Universidade Federal de Uberlândia, Uberlândia, 2016.

INPE. Instituto Nacional de Pesquisas Espaciais. Divisão de Geração de Imagens. Catálogo de Imagens. 2016. Disponível em: http://www.dgi.inpe.br/catalogo/. Acesso em 04 set. 2016.

IBGE. Instituto Brasileiro de Geografia e Estatística. Cidades. 2016. Disponível em: http://cidades.ibge.gov.br/xtras/perfil.php?lang=\&codmun=313160\&search=minas-gerais/iraide-minas. Acesso em 20 set. 2016.

KRUG, Thelma. Tecnologia espacial como suporte à gestão dos recursos naturais. Parcerias Estratégicas, Brasília-DF, v. 4, n. 7, p.211-226, 1999.

KLINK, C. A.; MACHADO, R. B. A conservação do Cerrado brasileiro. Megadiversidade, Rio de Janeiro, v. 1, n. 1, p.147-155, 2005.

MACHADO, Ricardo B. RAMOS NETO, Mário B; PEREIRA, PAULO G. P; CALDAS, Eduardo F; GONÇALVES, Nazareno S. Santos; TABOR, Karin; STEININGER, Marc..

Estimativas de perda da área do Cerrado brasileiro. Conservação Internacional, Brasília, 2004. Disponível em:

http://cmbbc.cpac.embrapa.br/RelatDesmatamCerrado\%20CIBrasil\%20JUL2004.pdf.

Acesso em 15 set. 2016.

MENESES, Paulo R.; ALMEIDA, Tati. Introdução ao processamento de imagens de sensoriamento remoto. Brasília: UNB/CNPq, 2012. Disponível em:

http://www.cnpq.br/documents/10157/56b578c4-0fd5-4b9f-b82a-e9693e4f69d8. Acesso em 10 set. 2016.

MYERS, N. MITTERMEIER, R. A.; MITTERMEIER, C. G.; FONSECA, G. A. B.; KENT, J. Biodiversity hotspots for conservation priorities. Nature, [s.i.], v. 403, n. 6772, p.853-858, 2000.

NOVO, Evlyn M. L. de M. Sensoriamento Remoto: Princípios e Aplicações. São Paulo: Edgard Blücher, 1989.

PONZONI, Flávio J.; SHIMABUKURO, Yosio E. Sensoriamento remoto no estudo da vegetação. São Jose dos Campos: Parêntese, 2007.

RICHARDS, John A. Remote Sensing Digital Image Analysis: An Introduction. Berlin: Springer-Verlag, 1986.

ROSENDO, Jussara dos S. Índices de Vegetação e Monitoramento do uso do solo e cobertura vegetal na Bacia do rio Araguari -MG - utilizando dados do sensor Modis. 2005. 130 p. Dissertação (Mestrado em Geografia e Gestão do Território), Uberlândia, 2005.

ROUSE, J. W.; HAAS, R. H.; SCHEEL, J.A; DECRING, D.W. Monitoring vegetation systems in the Great Plains with ERTS. NASA special publication, Texas, v. 351, p. 309, 1974. Disponível em: <https://ntrs.nasa.gov/archive/nasa/casi.ntrs.nasa.gov/19740022614.pdf>. Acesso em 12 dez. 2016.

SANO, E.; FERREIRA, L. G.; ASNER, G. P.; STEINKE, E. T. Spatial and temporal probabilities of obtaining cloud-free Landsat images over the Brazilian tropical savanna. International Journal of Remote Sensing, [s.i.], v. 28, n. 12, p.2739-2752, 2007. 


\section{NOTAS DE AUTOR}

\section{CONTRIBUIÇÃO DE AUTORIA}

Aracy Alves de Araújo - Concepção. Análise de dados, Elaboração do manuscrito, revisão e aprovação da versão final do trabalho.

Janderson Cristian Ferreira - Concepção e elaboração do manuscrito. Coleta de dados Participação ativa da discussão dos resultados.

Claudionor Riberio da Silva - Concepção e elaboração do manuscrito. Coleta de dados. Participação ativa da discussão dos resultados; Revisão e aprovação da versão final do trabalho.

\section{FINANCIAMENTO}

Não se aplica.

\section{CONSENTIMENTO DE USO DE IMAGEM}

"Não se aplica". As imagens orbitas usadas, da série Landsat, são fornecidas gratuitamente, para fins de pesquisas, no site do Instituto Nacional de Pesquisas Espaciais (INPE).

\section{APROVAÇÃO DE COMITÊ DE ÉTICA EM PESQUISA}

Não se aplica.

\section{CONFLITO DE INTERESSES}

Não se aplica.

\section{LICENÇA DE USO}

Este artigo está licenciado sob a Licença Creative Commons CC-BY. Com essa licença você pode compartilhar, adaptar, criar para qualquer fim, desde que atribua a autoria da obra.

\section{HISTÓRICO}

Recebido em: 04-06-2018

Aprovado em: 30-03-2019 